Original Research Paper

\title{
Influence of Curing Light Type and Staining Medium on the Discoloring Stability of Dental Restorative Composite
}

\author{
${ }^{1}$ Jamaluddin Syed, ${ }^{2}$ Ayman Al. Dharrab, ${ }^{3}$ Muhammad S. Zafa, ${ }^{4}$ Erum Khand, ${ }^{5}$ Raffaella Aversa, \\ ${ }^{6}$ Relly Victoria V. Petrescu, ${ }^{5}$ Antonio Apicella and ${ }^{6}$ Florian Ion T. Petrescu \\ ${ }^{I}$ Department of Oral Basic and Clinical Sciences, Advanced Technology Dental Research Laboratory, \\ Faculty of Dentistry, King Abdul Aziz University, Jeddah, Saudi Arabia \\ ${ }^{2}$ Department of Oral and Maxillofacial Prosthodontics, Advanced Technology Dental Research Laboratory, \\ Faculty of Dentistry, King Abdul Aziz University, Jeddah, Saudi Arabia \\ ${ }^{3}$ Department of Restorative Dentistry, College of Dentistry, Taibah University, Madinah Al Munawwarah, Saudi Arabia \\ ${ }^{4}$ Department of Dental Materials, Bhitai Dental and Medical College, Mirpurkhas, Pakistan \\ ${ }^{5}$ Advanced Material Lab, Department of Architecture and Industrial Design, \\ Second University of Naples, 81031 Aversa (CE) Italy \\ ${ }^{6}$ IFToMM, ARoTMM, Bucharest Polytechnic University, Bucharest, (CE) Romania
}

Article history

Received: 23-02-2017

Revised: $10-03-2017$

Accepted: 21-03-2017

Corresponding Author: Florian Ion T. Petrescu IFToMM, ARoTMM, Bucharest Polytechnic University, Bucharest, (CE) Romania

Email: scipub02@gmail.com

\begin{abstract}
Discoloration kinetics of 4 commercial nano-filled resin composites polymerized with LED and QTH source types in 4 different staining media held at $37^{\circ} \mathrm{C}$ are investigated. Quartz Tungsten Halogen (QTH) and Light Emitting Diode (LED) were used. Dental composites color change was monitored with a digital spectrophotometer at one, two and four weeks for quantitative comparison. The kinetics and intensities of the color change in accelerated aging tests in staining media were monitored and discussed. Discoloring followed diffusive driven kinetics. The four composites polymerized with QTH light showed higher differences in color change intensities compared to LED cured ones. All the QTH cured samples have shown significant higher variations of color changes intensities compared to LED samples $(\mathrm{p}<0.05)$. LED cured composite showed comparatively more stable initial shade persistence than QTH cured ones, which may be explained in terms of higher level of polymerization and surface hardness reached by the LED light cure resinous composite matrix.
\end{abstract}

Keywords: Bioengineering, Biomaterials, Biotechnology, Biochemistry, Bioactive Scaffolds

\section{Introduction}

Tooth coloured resin based composites have the benefit of better aesthetic properties and are widely used aesthetic restorative materials in modern dentistry (Rajkumar et al., 2011). Initially, resin composites were manufactured as chemically activated materials; two pastes system based on initiator (benzoyl peroxide) and activator (a tertiary amine such as N,N-dimethyl p toluidine) system. The key drawbacks of chemically activation are the limited working time, difficulty in finishing and colour stability (Anusavice, 2003). These drawbacks led to the development of light cured resin composites, which could provide a better control over working and finishing times while improving colour stability. In addition, light cured resin materials are activated by visible blue light (wavelength $=400-470$ $\mathrm{nm}$ ) hence avoiding from the hazardous effects of radiation. Light cured composites contain canphorquinone as photo-initiator which facilitates better control over working time and enhances colour stability (Rajkumar et al., 2011; Anusavice, 2003), but discolouration still remains the main concern.

In order to cure light activated resin composites, various types of light sources have been used including Quartz Tungsten Halogen (QTH) and Light Emitting Diode (LED).

The QTH system is comprised of a quartz bulb and tungsten filament that works in the halogen environment. In order to activate the canphorquinone initiator, the emitted light is filtered to dissipate heat and to transmit only the violet-blue part of the visible light spectrum. These systems produce a spectrum of 400-500 nm with an output range of $400-800 \mathrm{~mW} / \mathrm{cm}^{2}$ (Filipov and Vladimirov, 2006). There are several disadvantages of using QTH system, among these there are the prolonged curing time, the source larger 
size and the need of filters and fans to dissipate the generated heat (Yazici et al., 2007; Aversa et al., 2016a; 2016b; 2016c; 2016d; 2016e; 2016f; 2016g; 2016h; 2016i; 2016j; 2016k; 2016l; 2016m; 2016n; 2016o).

The LED systems include Gallium nitride blue diodes and silicon carbide diodes with a power output of $7 \mu \mathrm{W}$ (Park et al., 2005). The LEDs sources are generally cordless, lightweight, of compact size and powered by batteries. The wavelength is usually in the range of 400$500 \mathrm{~nm}$. All the emitted condensed light is fully utilized and no additional filters or cooling fan are required. Finally, due to the electronic natue of the emitted light, there is no drop in intensity and diodes do not need replacement (Christensen, 2002). The main disadvantages are the relatively high cost of the equipment and that the batteries require recharging.

Although no significant mechanical differences have been reported in the curing performance of QTH and LED systems (Campregher et al., 2007), the QTH light curing system tends to exhibit more yellowing of the resin composites upon curing (Brackett et al., 2007). Moreover, LED systems are often considered similar or comparatively better than QTH system in terms of the degree of polymerization (Hasler et al., 2006), polymerization shrinkage (Uhl et al., 2005), microleakage (Attar and Korkmaz, 2007), wear rate (Ramp et al., 2006), flexural properties (Keogh et al., 2004) and hardness (de Araújo et al., 2008).

Currently, there are no reports that compare these two systems in terms of colour changes during aging in staining media (Imirzalioglu et al., 2010; Rajkumar et al., 2011; Seghi et al., 1990). In these works it was hypothesized that both the source type and the amount of energy provided by the curing light can not only change the colour of the dental restorative materials but also its discolouration aptitude in staining beverages. The aim of this study was to investigate the variations in shade change in various beverages of dental nano-filled resin composite cured with QTH and LED light curing systems (Paul et al., 2002; Zafar, 2013; Zafar and Ahmed, 2015; Ullah and Zafar, 2015).

\section{Materials and Methods}

Two different light curing systems were evaluated on various resin composites for colour stability. A QTH light cure unit (Optilight Plus, Curing Light, Gnatus, Ribeirão Preto, SP, Brazil) and a LED cure unit (EliparTM LED Curing Light, 3M ESPE, Deutschland, $\mathrm{GmBH}, 41453$, Germany). The cured samples were conditioned in various staining beverages and analysed for time dependency of their colour changes (Table 1).

\section{Sample Preparation}

For each material, 100 disc shaped specimens $(6 \mathrm{~mm}$ diameter and $3 \mathrm{~mm}$ thickness) were prepared using specially tailor made Teflon moulds. A glass slide was used to compress and flatten the materials and to remove the excess resin. Before curing, all samples were divided randomly in to two study groups: QTH and LED $(\mathrm{n}=50$ for each group). QTH group samples were cured for twenty seconds using a halogen light source (Optilight Plus, Curing Light, Gnatus, Ribeirão Preto, SP, Brazil). LED groups samples were light cured for twenty seconds using a diode electronic light source (Elipar ${ }^{\mathrm{TM}}$ LED Curing Light, 3M ESPE, Deutschland, GmBH, 41453, Germany). Light sources were held at a distance of $2 \mathrm{~mm}$ from the surface of sample (Petrescu and Calautit, 2016a; 2016b; Petrescu et al., 2015; 2016a; 2016b; 2016c; 2016d; 2016e). All samples were inspected carefully for uniformity. Samples with any defect, visible crack or voids were excluded. Each sample was polished using a finishing discs kit (Sof-LEX disks; 3M ESPE, ST Paul.MN) and slow speed air turbine handpiece (uniform pressure and circular motions were used) according to manufacturer's guidelines. The final thickness of samples after polishing was $2.0 \pm 0.01 \mathrm{~mm}$. Prepared samples from each materials under investigation $(\mathrm{n}=100)$ were randomly divided into various study groups for longevity analysis (Fig. 1).

\section{Preparation of Beverage Solutions and Aging Treatment}

The effects of four hot beverages (karkada, tea, yansoon and coffee) on the colour stability after light curing were investigated (Table 1). All beverage solutions were prepared by boiling tea leave/coffee granules in deionized distilled water for $5 \mathrm{~min}$. Final concentration of each solution was maintained at 3.5\% and $\mathrm{pH}$ in the range of 3.5-4.5. The $\mathrm{pH}$ of the solution was maintained throughout the experimental period using a digital $\mathrm{pH}$ meter (Clean PH500, First Clean Co. 14656 Valley Blvd, City of Industry, 91746). Additives such as sugar, milk or flavourings were not added to any experimental solutions.

Specimens were immersed in $50 \mathrm{~mL}$ of ageing media in air tight containers and were stored in an incubator at $37^{\circ} \mathrm{C}$. Ageing beverage medium was changed cyclically after every $6 \mathrm{~h}$ to mimic the daily consumption of the beverage daily. Specimens were rinsed using deionized water before colour shade measuring and change of the ageing beverage media.

Five groups of samples for each curing light source type were prepared: Karkada [Group I; $n=10$ ]; black tea [Group II; $\mathrm{n}=10$ ]; yansoon [Group III; $\mathrm{n}=10$ ]; coffee [Group IV; $\mathrm{n}=10$ ]; deionized distilled water used as control group for aging $(\mathrm{n}=10)$.

\section{Assessment of Colour Longevity}

The longevity of the dental composites in staining media was evaluated by recording the colour changes. A digital spectrophotometer Chroma Meter (CR 400; Konik Minolta, Japan) has been used to perform a colorimetric analysis to quantitatively monitor the colour changes in each restorative composites sample aged for one, two and four weeks of staining liquid conditioning. 


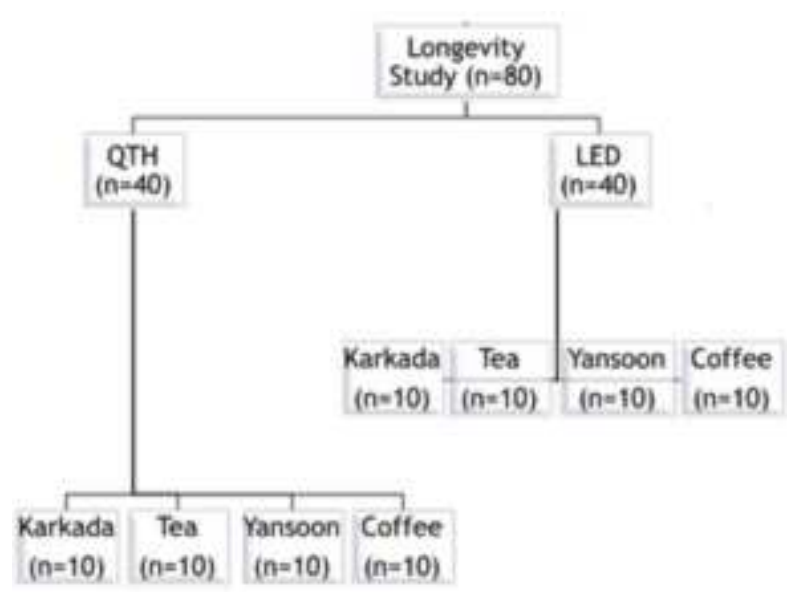

Fig. 1. Schematic presentation of study design, groups and sample distribution

Table 1. Restorative materials and beverages

\begin{tabular}{llll}
\hline & & Description & Manufacturer \\
\hline Restorative materials & & Resin based nanocomposite & 3M ESPE, St. Paul, MN 55144-1000 USA \\
Filtek Z350 XT & A & Resin based nanocomposite & 3M ESPE, St. Paul, MN 55144-1000 USA \\
Filtek Z250 XT & B & Nanocomposite resin composite & Pentron Clinical Orange CA, 92867, USA \\
Artiste & C & Capsule Glass ionomer & GC Corporation, Tokyo, Japan \\
GC Fuji II LC & D & & \\
Beverages used & & Herbal Tea & Al Diafa, J.N. Spain \\
Karkada & I & Black Tea & Al Diafa, J.N. Spain \\
Tea & II & Herbal Tea & Lipton yellow label, Riyadh, Saudi Arabia \\
Yansoon & III & Instant freeze dried coffee & Nescafe, Original, USA \\
Coffee & IV & &
\end{tabular}

The spectrophotometer returned a precise quantitative measurement of surface colours by recording the spectral reflectance/transmittance curve of the specimen.

A prism disperses tungsten-filament bulb light into a spectrum of wavelength (5 and $20 \mathrm{~nm}$ ) bands (Bowen and Marjenhoff, 1992; Kim-Pusateri et al., 2007; Dozić et al., 2007; Al-Dharrab, 2013; Eldiwany et al., 1995; Ruchi et al., $2010)$. The colour changes $(\Delta E)$ of each specimen were calculated by analysing the coordinate values before and after beverage ageing. Colour changes were quantified using the following equation (Imirzalioglu et al., 2010):

$$
\Delta E a b=\left[(\Delta L)^{2}+(\Delta a)^{2}+(\Delta b)^{2}\right]^{1 / 2}
$$

Where:

$\Delta E a b=$ The overall colour difference

$\Delta L \quad=$ The lightness

$\Delta a=$ The red colour on the positive and the green colour on the negative side

$\Delta b=$ The yellow colour on the positive and the blue colour on the negative side

The results were statistically analysed by using SPSS version 20 and $95 \%$ Confidence Intervals (CI). Chi-square tests were used to evaluate the experimental data significance. A $P$-value $<0.05$ was considered significant.
The regression parameter $\left(\mathrm{R}^{2}\right)$, which measures the relationship between the two variables colour change and time, was evaluated for all staining tests at significance $\mathrm{p}<0.05$.

\section{Results}

All samples exhibited increasing discoloration with time upon ageing in the staining liquids.

Discolouring kinetics was investigated by plotting the digital spectrophotometry colour change values as a function of the exposure time.

The colour changes linearly related to the square root of time (Fig. 2) with a near unity regression parameter (last column of Table 2).

All colour changes data were grouped for type of composite resin, cure light and staining beverage and plotted as a function of the square root of time. Significant differences in staining properties among the four beverages (karkada, tea, coffee and yansoon were observed (Fig 3a through d).

Figure 3a-c show the colour changes observed for GC Fuji II LC, Filtek Z250 XT and Filtek Z350 XT, respectively. The colour differences between LED and QTH cured samples become higher and statistically significant at week 2 and week 4 for all beverages. 

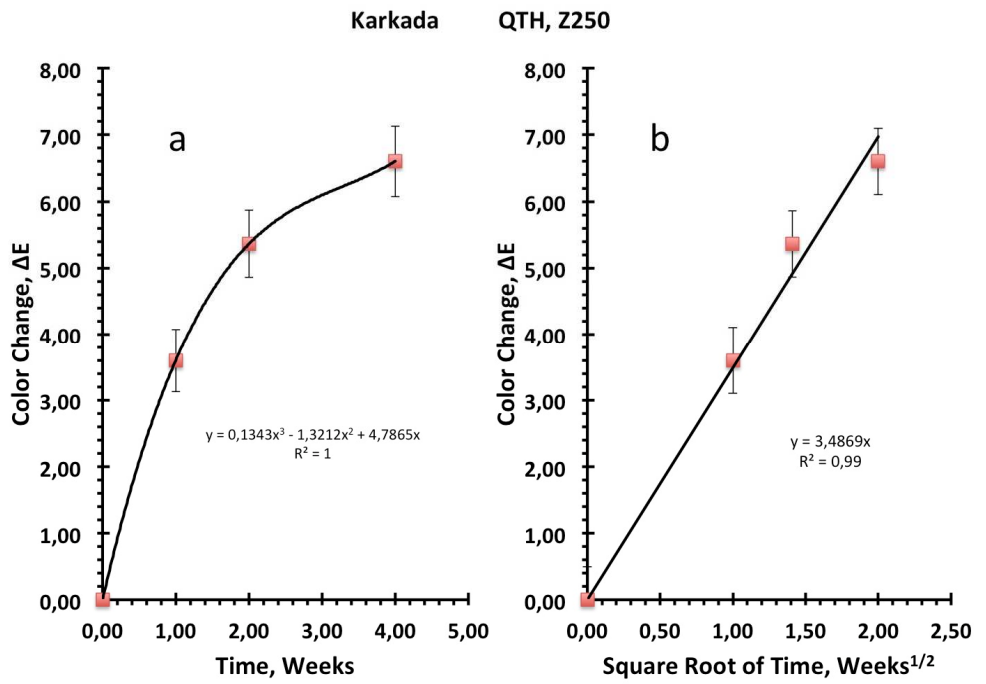

Fig. 2. Discolouring kinetics of QTH cured Z250 restorative resin composite in karkada beverage plotted as a function of time (a) and of the square route of time (b)
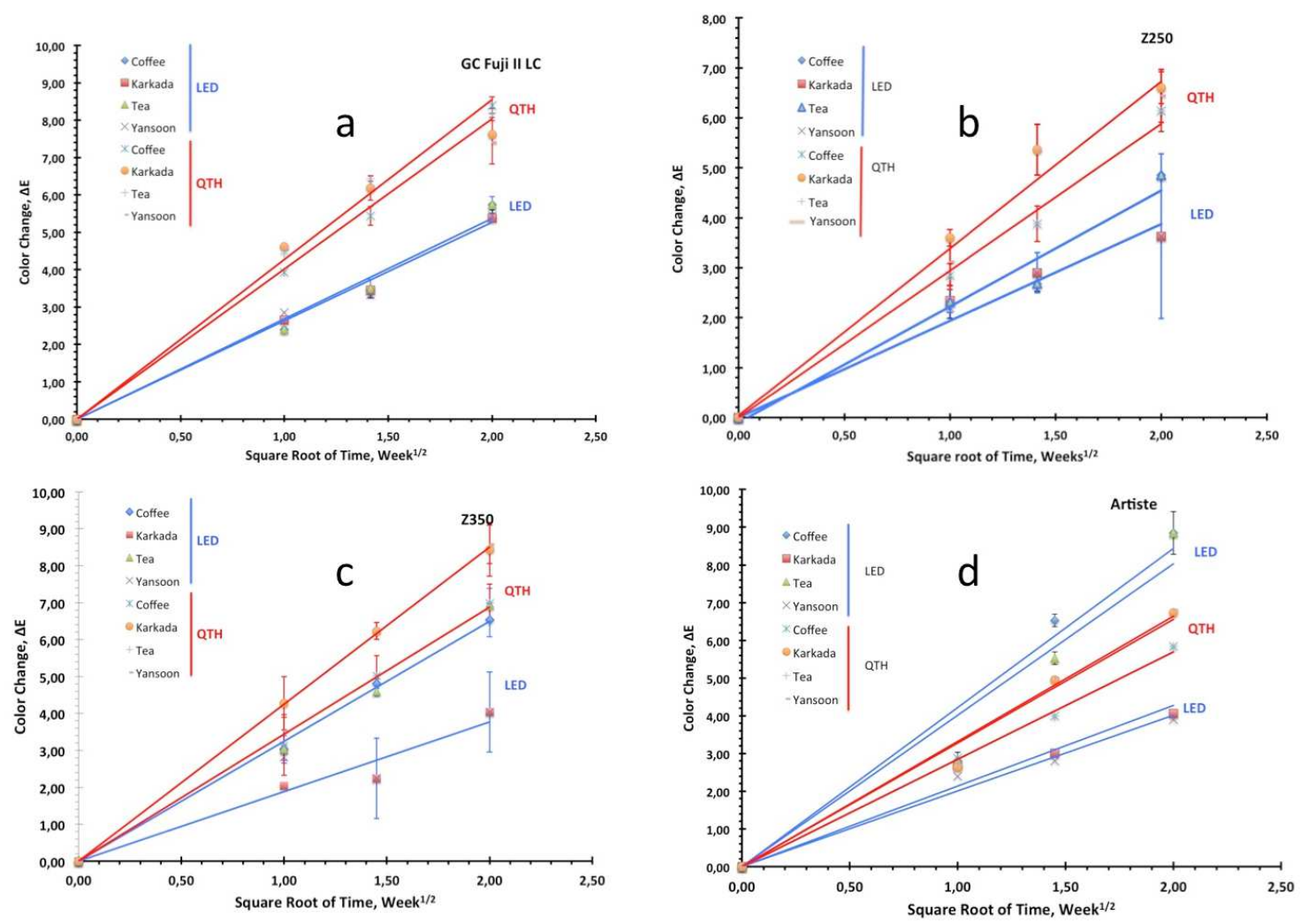

Fig. 3. Diffusion controlled discoloring kinetic for QTH cured (red lines) and LED cured (blue lines) for (a) GC Fuji II LC, (b) Z250, (c) Z350, (d) Artiste resin composites in different staining media

The colour differences following aging in any of the staining media (Fig. 3a and raw data in Table 2) were significantly higher for QTH light cured samples (red regression lines in the figure) than for LED cured specimens (blue regression lines in the figure). QTH and LED cured samples reached at four weeks mean grade colour changes for GC Fuji II LC of $15.60 \pm 0.19$ and $7.90 \pm 0.47$, respectively. Filtek Z250 XT reached $6.33 \pm 0.23$ and $4.24 \pm 0.71$ respectively for QTH and LED. Tea and coffee produced slightly higher discolouring compared to yansoon and karkada both for QTH and LED cured composites. 
Table 2. The summary statistics of response variable ( $\Delta \mathrm{E}_{\mathrm{ab}}$ values) at week1, week 2 and week 4 by light type with four different types of beverages for restorative materials

\begin{tabular}{|c|c|c|c|c|c|}
\hline Cure light & Beverage & Week $=1 \mathrm{Week}^{1 / 2}=1$ & Week $=2 \mathrm{Week}^{1 / 2}=1.4$ & Week $=4 \mathrm{Week}^{1 / 2}=2$ & Linear Regr., $\mathrm{R}^{2}$ \\
\hline & Artiste & & & & \\
\hline \multirow[t]{4}{*}{ LED } & Coffee & $2.80 \pm 0.23$ & $6.53 \pm 0.17$ & $8.85 \pm 0.57$ & 0,955 \\
\hline & Karkada & $2.70 \pm 0.05$ & $3.01 \pm 0.31$ & $4.05 \pm 0.91$ & 0,964 \\
\hline & Tea & $2.80 \pm 0.23$ & $5.53 \pm 0.17$ & $8.85 \pm 0.57$ & 0,957 \\
\hline & Yansoon & $2.56 \pm 0.16$ & $3.01 \pm 0.27$ & $4.05 \pm 0.79$ & 0,981 \\
\hline \multirow[t]{5}{*}{ QTH } & Coffee & $2.88 \pm 0.20$ & $4.00 \pm 0.34$ & $5.84 \pm 0.52$ & 0,998 \\
\hline & Karkada & $2.63 \pm 0.24$ & $4.95 \pm 0.62$ & $6.74 \pm 0.48$ & 0,983 \\
\hline & Tea & $2.72 \pm 0.35$ & $4.00 \pm 0.34$ & $5.84 \pm 0.52$ & 0,997 \\
\hline & Yansoon & $2.70 \pm 0.12$ & $5.01 \pm 0.56$ & $6.80 \pm 0.22$ & 0,985 \\
\hline & GC Fuji II LC & & & & \\
\hline \multirow[t]{4}{*}{ LED } & Coffee & $2.40 \pm 0.25$ & $3.49 \pm 0.22$ & $5.74 \pm 0.07$ & 0,992 \\
\hline & Karkada & $2.65 \pm 0.42$ & $3.46 \pm 0.31$ & $5.44 \pm 0.14$ & 0,997 \\
\hline & Tea & $2.40 \pm 0.25$ & $3.49 \pm 0.22$ & $5.74 \pm 0.07$ & 0,992 \\
\hline & Yansoon & $2.85 \pm 0.09$ & $3.34 \pm 0.16$ & $5.44 \pm 0.14$ & 0,992 \\
\hline \multirow[t]{5}{*}{ QTH } & Coffee & $3.40 \pm 0.15$ & $5.44 \pm 0.12$ & $8.40 \pm 0.03$ & 0,998 \\
\hline & Karkada & $4.62 \pm 0.38$ & $6.18 \pm 0.58$ & $7.62 \pm 0.82$ & 0,990 \\
\hline & Tea & $4.43 \pm 0.08$ & $6.44 \pm 0.12$ & $8.20 \pm 0.46$ & 0,996 \\
\hline & Yansoon & $4.57 \pm 0.32$ & $6.18 \pm 0.58$ & $7.41 \pm 0.40$ & 0,987 \\
\hline & $\mathrm{Z} 250$ & & & & \\
\hline \multirow[t]{4}{*}{ LED } & Coffee & $2.32 \pm 0.33$ & $2.69 \pm 0.16$ & $4.86 \pm 0.01$ & 0,969 \\
\hline & Karkada & $2.34 \pm 0.21$ & $2.90 \pm 0.40$ & $3.63 \pm 1.65$ & 0,973 \\
\hline & Tea & $2.32 \pm 0.33$ & $2.69 \pm 0.16$ & $4.86 \pm 0.01$ & 0,969 \\
\hline & Yansoon & $2.20 \pm 0.10$ & $2.90 \pm 0.40$ & $3.63 \pm 1.65$ & 0,983 \\
\hline \multirow[t]{5}{*}{ QTH } & Coffee & $2.84 \pm 0.10$ & $3.88 \pm 0.35$ & $6.14 \pm 0.41$ & 0,993 \\
\hline & Karkada & $3.60 \pm 0.47$ & $5.36 \pm 0.51$ & $6.60 \pm 0.53$ & 0,988 \\
\hline & Tea & $2.83 \pm 0.26$ & $3.88 \pm 0.35$ & $6.14 \pm 0.41$ & 0,993 \\
\hline & Yansoon & $3.12 \pm 0.16$ & $5.36 \pm 0.51$ & $6.44 \pm 0.32$ & 0,979 \\
\hline & $\mathrm{Z} 350$ & & & & \\
\hline \multirow[t]{4}{*}{ LED } & Coffee & $3.03 \pm 0.38$ & $4.81 \pm 0.13$ & $6.93 \pm 0.45$ & 0,998 \\
\hline & Karkada & $2.05 \pm 0.03$ & $2.24 \pm 1.09$ & $4.04 \pm 1.09$ & 0,959 \\
\hline & Tea & $3.03 \pm 0.38$ & $4.60 \pm 0.14$ & $6.93 \pm 0.45$ & 0,993 \\
\hline & Yansoon & $2.83 \pm 0.10$ & $2.24 \pm 1.09$ & $4.04 \pm 1.09$ & 0,876 \\
\hline \multirow[t]{4}{*}{ QTH } & Coffee & $3.13 \pm 0.76$ & $5.03 \pm 0.54$ & $6.58 \pm 0.25$ & 0,996 \\
\hline & Karkada & $4.28 \pm 0.72$ & $6.23 \pm 0.23$ & $8.44 \pm 0.73$ & 0,872 \\
\hline & Tea & $3.15 \pm 0.82$ & $5.03 \pm 0.54$ & $7.00 \pm 0.51$ & 0,844 \\
\hline & Yansoon & $3.52 \pm 0.38$ & $6.23 \pm 0.23$ & $8.58 \pm 0.52$ & 0,808 \\
\hline
\end{tabular}

The Z350 showed similar behaviour with yet statistically significant grade change values at four weeks between $7.75 \pm 0.88$ and $5.39 \pm 1.56$ for QTH and LED light curing, respectively. It has been observed that both Z250 and Z350, either for QTH and LED light curing, were more sensitive to discolouring induced by karkada and yansoon.

A more complex staining behaviour was observed for LED cured Artiste composite (Fig. 3d); a higher sensitivity to discolouration of the QTH cured Artiste composite with respect to the LED cured ones was observed for staining induced by karkada and yansoon $(3.98 \pm 0.11$ for LED cured and about $6.5 \pm 0.54$ for QTH), while, contrarily to all the previous discussed systems, LED cured composite presented significantly higher discolouring compared to QTH ones when exposed to coffee and tea $(8.86 \pm 0.01$ for LED and about $5.84 \pm 0.01$ for QTH light cures, respectively). Less significant differences in discolouring properties of the staining media were observed among the
QTH cured samples (mean discolouring grade values ranged from $5.84 \pm 0.01$ to $6.5 \pm 0.54$ ).

\section{Discussion}

The resin composites gained popularity as restorative material due to their aesthetic properties such as translucency and colour matching to natural teeth (Rajkumar et al., 2011). Ideally, restorative materials should have a matching shade that is stable for colour changes over a long period of time. Nevertheless, these materials have been described to change their colour with time in response to various oral environmental, intrinsic and extrinsic factors (Rajkumar et al., 2011).

Colour changes in the composite polymeric matrix are induced by the diffusion and absorption of increasing amount of chromogenic staining substances. A square root of the time dependency of the colour change was observed in our tests. All mass transfer processes driven 
by diffusive phenomena, in fact, are described by a linear behaviour in the early sorption stages when plotted as a function of the square root of the time (Crank, 1975). Sorption and diffusion of the chromogenic substance in the composite polymeric matrix will increase the concentration of the staining substance, which, then, will progressively alter the colour shade.

Moreover, colour change of resin composites on curing has been described to show characteristic variations in terms of chrome values (Seghi et al., 1990). In the current study, the intrinsic colour stability of dental resin composites curing using QTH or LED light has been evaluated.

The effect of aging on cured materials in different staining beverages was also studied. A large number of electronic devices (spectrophotometers, colorimeters, digital colour analysers, or their combinations) are presently available for clinical use (Paul et al., 2002).

In terms of curing light source, LED curing resulted in less colour changes and better stability for all composites.

In QTH curing system, the light is mainly dissipated as heat. The excessive heat may increase the temperature of restoration and likely favour oxidation processes affecting the subsequent staining substances sorption attitude.

Conversely, the energy emitted by LED curing system is fully used with less heat dispersion avoiding potential oxidation processes. QTH cured composites have been described to exhibited more yellowing of upon curing (Brackett et al., 2007). In our accelerated aging tests, QTH curing showed more intrinsic colour changes attitude than LED curing for all tested composites materials. GC Fuji II LC showed the more remarkable colour variations upon ageing. This composite belongs to the class of the glass ionomers that are used for their fluoride release in the oral cavity (Zafar, 2013; Zafar and Ahmed, 2015). Based on the fact that GC Fuji II LC materials are more prone to colour changes upon curing and aging, they should not be considered as the best choice for aesthetic restorations (Bowen and Marjenhoff, 1992).

A number of factors including nature of light, its intensity, type of measuring tools and experimental procedures during shade assessment may lead to inaccurate measurements (Apicella et al., 2005; Simeone et al., 2005; Kim-Pusateri et al., 2007; Dozić et al., 2007).

Although the effects of curing by LED and QTH have been compared in previous studies (Al-Dharrab, 2013), there is no published complete study comparing the effects in terms of colour changes during aging in staining media.

Recently, QTH and LED have been compared for their curing performance and effectiveness in terms of hardness and depth of cure. In terms of depth of cure, LED has been reported to cure similar or to increase depths through the resin composites (Apicella et al., 2002; 2005; Simeone et al., 2005; Ruchi et al., 2010). Considering the surface micro-hardness, several studies
(Yaman et al., 2011) reported that LED-curing results is better micro-hardness than QTH. These results are suggesting that the type of curing light source may affect the level of polymerization and cross linking of the resin through the composite leading to higher surface hardness and glass transition temperatures.

Although our current study has a number of limitations due to the lack of dynamic stimulation of a real oral environment and clinical conditions (Aversa et al., 2009; Sorrentino et al., 2007; 2009; Perillo et al., 2010; Gramanzini et al., 2016; Marrelli et al., 2015), the base mechanisms and kinetics of resin composite staining have been identified and discussed.

QTH cured materials have shown almost in all tested samples higher discolorations than LED cured materials (with the exception of coffee and black tea in LED cured Artiste). The colour changes induced by the different beverages (karkada, tea, coffee or yansoon) were different for each material and exposure time leading to the conclusion that we are dealing with intrinsic discolouring driven by staining species sorption and diffusive phenomena in the polymeric composite matrix.

The specific sensitivity of each material could depend both on the resinous chemical nature and on the levels of polymerization and undesired chemical changes that are singularly reached by the resinous systems upon curing.

\section{Conclusion}

Discoloration kinetics of 4 commercial nano-filled resin composites polymerized with LED and QTH source types in 4 different staining media held at $37^{\circ} \mathrm{C}$ are investigated. Quartz Tungsten Halogen (QTH) and Light Emitting Diode (LED) were used. Dental composites color change was monitored with a digital spectrophotometer at one, two and four weeks for quantitative comparison.

The kinetics and intensities of the color change in accelerated aging tests in staining media were monitored and discussed. Discoloring followed diffusive driven kinetics. The four composites polymerized with QTH light showed higher differences in color change intensities compared to LED cured ones. All the QTH cured samples have shown significant higher variations of color changes intensities compared to LED samples $(\mathrm{p}<0.05)$. LED cured composite showed comparatively more stable initial shade persistence than QTH cured ones, which may be explained in terms of higher level of polymerization and surface hardness reached by the LED light cure resinous composite matrix.

QTH cured materials have shown almost in all tested samples higher discolorations than LED cured materials (with the exception of coffee and black tea in LED cured Artiste). The colour changes induced by the different beverages (karkada, tea, coffee or yansoon) were different for each material and exposure time leading to the conclusion that we are dealing with intrinsic 
discolouring driven by staining species sorption and diffusive phenomena in the polymeric composite matrix.

The specific sensitivity of each material could depend both on the resinous chemical nature and on the levels of polymerization and undesired chemical changes that are singularly reached by the resinous systems upon curing.

\section{Acknowledgement}

The authors would like to appreciate the facilities and assistance provided by the Advanced Technology Dental Research Laboratory, Faculty of dentistry, King Abdul Aziz University. The authors would also appreciate the research technicians, Basim Al Turki and Fahad Al Othaibi for their cooperation.

\section{Author's Contributions}

All the authors contributed equally to prepare, develop and carry out this manuscript.

\section{Ethics}

This article is original and contains unpublished material. The corresponding author confirms that all of the other authors have read and approved the manuscript and no ethical issues involved.

\section{References}

Al-Dharrab, A., 2013. Effect of energy drinks on the color stability of nanofilled composite resin. J. Contemporary Dental Pract., 14: 704-711. PMID: 24309352

Anusavice, K.J., 2003. Phillips' Science of Dental Materials. 11th Edn., Elsevier Health Sciences, St. Louis, ISBN-10: 143772549X, pp: 832.

Apicella, A., L. Di Palma, R. Aversa and P. Ausiello, 2002. DSC kinetic characterization of dental composites using different light sources. J. Adv. Mater., 34: 22-25.

Apicella, A., M. Simeone, R. Aversa, A. Lanza and D. Apicella, 2005. Light shielding effect of overlaying resin composite on the photopolymerization cure kinetics of a resin composite and a dentin adhesive. Dental Mater., 21: 954-961.

DOI: 10.1016/j.dental.2004.09.012

Attar, N. and Y. Korkmaz, 2007. Effect of two LightEmitting Diode (LED) and one halogen curing light on the microleakage of Class $\mathrm{V}$ flowable composite restorations. J. Contemp. Dent. Pract., 8: 80-88. PMID: 17277830

Aversa, R., D. Apicella, L. Perillo, R. Sorrentino and F. Zarone et al., 2009. Non-linear elastic threedimensional finite element analysis on the effect of endocrown material rigidity on alveolar bone remodeling process. Dental Mater., 25: 678-690. PMID: 19150574
Aversa, R., F.I.T. Petrescu, R.V. Petrescu and A. Apicella, 2016a. Biomimetic FEA bone modeling for customized hybrid biological prostheses development. Am. J. Applied Sci., 13: 1060-1067. DOI: 10.3844/ajassp.2016.1060.1067

Aversa, R., D. Parcesepe, R.V. Petrescu, G. Chen and F.I.T. Petrescu et al., 2016b. Glassy amorphous metal injection molded induced morphological defects. Am. J. Applied Sci., 13: 1476-1482. DOI: 10.3844 /ajassp.2016.1476.1482

Aversa, R., R.V. Petrescu, F.I.T. Petrescu and A. Apicella, 2016c. Smart-factory: Optimization and process control of composite centrifuged pipes. Am. J. Applied Sci., 13: 1330-1341. DOI: 10.3844/ajassp.2016.1330.1341

Aversa, R., F. Tamburrino, R.V. Petrescu, F.I.T. Petrescu and M. Artur et al., 2016d. Biomechanically inspired shape memory effect machines driven by muscle like acting NiTi alloys. Am. J. Applied Sci., 13: 1264-1271. DOI: 10.3844/ajassp.2016.1264.1271

Aversa, R., E.M. Buzea, R.V. Petrescu, A. Apicella and M. Neacsa et al., 2016e. Present a mechatronic system having able to determine the concentration of carotenoids. Am. J. Eng. Applied Sci., 9: 1106-1111. DOI: 10.3844/ajeassp.2016.1106.1111

Aversa, R., R.V. Petrescu, R. Sorrentino, F.I.T. Petrescu and A. Apicella, 2016f. Hybrid ceramo-polymeric nanocomposite for biomimetic scaffolds design and preparation. Am. J. Eng. Applied Sci., 9: 1096-1105. DOI: 10.3844/ajeassp.2016.1096.1105

Aversa, R., V. Perrotta, R.V. Petrescu, C. Misiano and F.I.T. Petrescu et al., 2016g. From structural colors to super-hydrophobicity and achromatic transparent protective coatings: Ion plating plasma assisted $\mathrm{TiO}_{2}$ and $\mathrm{SiO}_{2}$ nano-film deposition. Am. J. Eng. Applied Sci., 9: 1037-1045.

DOI: 10.3844/ajeassp.2016.1037.1045

Aversa, R., R.V. Petrescu, F.I.T. Petrescu and A. Apicella, 2016h. Biomimetic and evolutionary design driven innovation in sustainable products development. Am. J. Eng. Applied Sci., 9: 1027-1036. DOI: 10.3844/ajeassp.2016.1027.1036

Aversa, R., R.V. Petrescu, A. Apicella and F.I.T. Petrescu, 2016i. Mitochondria are naturally micro robots - a review. Am. J. Eng. Applied Sci., 9: 991-1002. DOI: 10.3844/ajeassp.2016.991.1002

Aversa, R., R.V. Petrescu, A. Apicella and F.I.T. Petrescu, 2016j. We are addicted to vitamins $\mathrm{C}$ and E-A review. Am. J. Eng. Applied Sci., 9: 1003-1018. DOI: 10.3844 /ajeassp.2016.1003.1018

Aversa, R., R.V. Petrescu, A. Apicella and F.I.T. Petrescu, 2016k. Physiologic human fluids and swelling behavior of hydrophilic biocompatible hybrid ceramo-polymeric materials. Am. J. Eng. Applied Sci., 9: 962-972. DOI: 10.3844/ofsp.10850 
Aversa, R., R.V. Petrescu, A. Apicella and F.I.T. Petrescu, 20161. One can slow down the aging through antioxidants. Am. J. Eng. Applied Sci., 9: 11121126. DOI: 10.3844/ajeassp.2016.1112.1126

Aversa, R., R.V. Petrescu, A. Apicella and F.I.T. Petrescu, 2016m. About homeopathy or «Similia Similibus Curentur 》. Am. J. Eng. Applied Sci., 9: 1164-1172. DOI: 10.3844/ajeassp.2016.1164.1172

Aversa, R., R.V. Petrescu, A. Apicella and F.I.T. Petrescu, 2016n. The basic elements of life's. Am. J. Eng. Applied Sci., 9: 1189-1197.

Aversa, R., F.I.T. Petrescu, R.V. Petrescu and A. Apicella, 2016o. Flexible stem trabecular prostheses. Am. J. Eng. Applied Sci., 9: 1213-1221.

DOI: $10.3844 /$ ofsp. 10946

Bowen, R.L. and W.A. Marjenhoff, 1992. Dental composites/glass ionomers: The materials. Adv. Dental Res., 6: 44-49. PMID: 1292462

Brackett, M.G., W.W. Brackett, W.D. Browning and F.A. Rueggeberg, 2007. The effect of light curing source on the residual yellowing of resin composites. Oper. Dent., 32: 443-450. PMID: 17910220

Campregher, U.B., S.M. Samuel, C.B. Fortes, A.D. Medina and F.M. Collares et al., 2007. Effectiveness of second-generation Light-Emitting Diode (LED) light curing units. J. Contemp. Dent. Pract., 8: 35-42. PMID: 17277825

Christensen, G.J., 2002. The curing light dilemma. J. Am. Dent. Assoc., 133: 761-763. PMID: 12083654

Crank, J., 1975. The Mathematics of Diffusion. 2nd Edn., Clarendon Press, Oxford, pp: 414.

de Araújo, C.S., M. Schein, C.H. Zanchi, S.A. Jr, Rodrigues and F.F. Demarco, 2008. Composite resin microhardness: The influence of light curing method, composite shade and depth of cure. J. Contemp. Dent. Pract., 9: 43-50. PMID: 18473026

Dozić, A., C.J. Kleverlaan, A. El Zohairy, A.J. Feilzer and G. Khashayar, 2007. Performance of five commercially available tooth color-measuring devices. J. Prosthodont., 16: 93-100. PMID: 17362418

Eldiwany, M., K.H. Friedl and J.M. Powers, 1995. Color stability of light-cured and post-cured composites. Am. J. Dent., 8: 179-181. PMID: 7576383

Filipov, I.A. and S.B. Vladimirov, 2006. Residual monomer in a composite resin after light-curing with different sources, light intensities and spectra of radiation. Braz. Dent. J., 17: 34-38. DOI: $10.1590 / \mathrm{S} 0103-64402006000100008$

Gramanzini, M., S. Gargiulo, F. Zarone, R. Megna and A. Apicella et al., 2016. Combined microcomputed tomography, biomechanical and histomorphometric analysis of the peri-implant bone: A pilot study in minipig model. Dent. Mater., 32: 794-806. PMID: 27063459

Hasler, C., B. Zimmerli and A. Lussi, 2006. Curing capability of halogen and LED light curing units in deep class II cavities in extracted human molars. Oper. Dent., 31: 354-363. PMID: 16802644
Imirzalioglu, P., O. Karacaer, B. Yilmaz and I. Ozmen Msc, 2010. Color stability of denture acrylic resins and a soft lining material against tea, coffee and nicotine. J. Prosthodont., 19: 118-124. PMID: 20002978

Keogh, P., N.J. Ray, C.D. Lynch and A. Hannigan, 2004. Surface microhardness of a resin composite exposed to a "first-generation" LED curing lamp, in vitro. Eur. J. Prosthodont. Restor. Dent., 12: 177-180.

Kim-Pusateri, S., J.D. Brewer, R.G. Dunford and A.G. Wee, 2007. In vitro model to evaluate reliability and accuracy of a dental shade-matching instrument. J. Prosthet. Dent., 98: 353-358. PMID: 18021823

Marrelli, M., G. Falisi, A. Apicella, D. Apicella and M. Amantea et al., 2015. Behaviour of dental pulp stem cells on different types of innovative mesoporous and nanoporous silicon scaffolds with different functionalizations of the surfaces. J. Biol. Regulators Homeostat. Agents, 29: 991-997. PMID: 26753666

Park, S.H., S.S. Kim, Y.S. Cho, S.Y. Lee and B.D. Noh, 2005. Comparison of linear polymerization shrinkage and microhardness between QTH-cured and LED-cured composites. Oper. Dent., 30: 461-467. PMID: 16130866

Paul, S., A. Peter, N. Pietrobon and C.H. Hämmerle, 2002. Visual and spectrophotometric shade analysis of human teeth. J. Dent. Res., 81: 578-582. PMID: 12147751

Perillo, L., R. Sorrentino, D. Apicella, A. Quaranta and E. Gherlone et al., 2010. Nonlinear visco-elastic finite element analysis of porcelain veneers: A submodelling approach to strain and stress distributions in adhesive and resin cement. J. Adhesive Dent., 12: 403-413. PMID: 20157681

Petrescu, F.I.T. and K.J. Calautit, 2016a. About nano fusion and dynamic fusion. Am. J. Applied Sci., 13: 261-266. DOI: 10.3844/ajassp.2016.261.266

Petrescu, F.I.T. and K.J. Calautit, 2016b. About the light dimensions. Am. J. Applied Sci., 13: 321-325. DOI: 10.3844 /ajassp.2016.321.325

Petrescu, F.L., E. Buzea, L. Nănuț, M. Neacşa and C. Nan, 2015. The role of antioxidants in slowing aging of skin in a human, Analele Univers. Craiova Biologie Horticultura Tehn. Prel. Prod. Agr. Ing. Med., 20: 567-574.

Petrescu, F.I.T., A. Apicella, R. Aversa, R.V. Petrescu and J.K. Calautit et al., 2016a. Something about the mechanical moment of Inertia. Am. J. Applied Sci., 13: 1085-1090. DOI: 10.3844/ajassp.2016.1085.1090

Petrescu, R.V., R. Aversa, A. Apicella, S. Li and G. Chen et al., 2016b. Something about electron dimension. Am. J. Applied Sci., 13: 1272-1276. DOI: 10.3844/ajassp.2016.1272.1276

Petrescu, R.V., R. Aversa, A. Apicella, F. Berto and $\mathrm{S}$. Li et al., 2016c. Ecosphere protection through green energy. Am. J. Applied Sci., 13: 1027-1032. DOI: 10.3844/ajassp.2016.1027.1032 
Petrescu, F.I.T., A. Apicella, R.V. Petrescu, S.P. Kozaitis and R.B. Bucinell et al., 2016d. Environmental protection through nuclear energy. Am. J. Applied Sci., 13: 941-946.

Petrescu, R.V., R. Aversa, A. Apicella and F.I.T. Petrescu, 2016e. Future medicine services robotics. Am. J. Eng. Applied Sci., 9: 1062-1087.

DOI: 10.3844/ajeassp.2016.1062.1087

Rajkumar, K., S. Kumar, S. Mahalaxmi, P. Ragavi and T.A. Mageshwaran, 2011. Color stability of resin composites after immersing in coffee of different temperature - An in vitro study. SRM Univ. J. Dent. Sci., 2: 91-95.

Ramp, L.C., J.C. Broome and M.H. Ramp, 2006. Hardness and wear resistance of two resin composites cured with equivalent radiant exposure from a low irradiance LED and QTH light-curing units. Am. J. Dent., 19: 31-36. PMID: 16555655

Ruchi, D., S. Jaideep and D. Arunagiri, 2010. A comparative study of Degree of Conversion (DOC) of hybrid composite resins with nanocomposite resins when exposed to Visible Light Cure (VLC) unit and Light Emitting Diodes (LED)-an in vitro study. Ind. J. Dent. Sci., 2: 6-9.

Seghi, R., M. Gritz and J. Kim, 1990. Colorimetric changes in composites resulting from visible-lightinitiated polymerization. Dent. Mater., 6: 133-137. PMID: 2079174

Simeone, M., A. Lanza, S. Rengo, R. Aversa and D. Apicella et al., 2005. Inlay shading effect on the photopolymerization kinetic of a dental composite material used as bonding system in an indirect restoration technique. Dent. Mater., 21: 689-694. PMID: 15963562

Sorrentino, R., R. Aversa, V. Ferro, T. Auriemma and F. Zarone et al., 2007. Three-dimensional finite element analysis of strain and stress distributions in endodontically treated maxillary central incisors restored with different post, core and crown materials. Dent. Mater., 23: 983-993. PMID: 17070903
Sorrentino, R., D. Apicella, C. Riccio, E.D. Gherlone and F. Zarone et al., 2009. Nonlinear visco-elastic finite element analysis of different porcelain veneers configuration. J. Biomed. Mater. Res. -Part B Applied Biomater., 91: 727-736. PMID: 19582860

Uhl, A., R.W. Mills, A.E. Rzanny and K.D. Jandt, 2005. Time dependence of composite shrinkage using halogen and LED light curing. Dent. Mater., 21: 278-286. PMID: 15705435

Ullah, R. and M.S. Zafar, 2015. Oral and dental delivery of fluoride: A review. Fluoride, 48: 195-204. DOI: $10.4103 / 2231-0762.165927$

Yaman, B.C., B.G. Efes, C. Dorter, Y. Gömeç and D. Erdilek et al., 2011. The effects of halogen and lightemitting diode light curing on the depth of cure and surface microhardness of composite resins. J. Conserv. Dent., 14: 136-139. DOI: 10.4103/0972-0707.82613

Yazici, A.R., G. Kugel and G. Gul, 2007. The Knoop hardness of a composite resin polymerized with different curing lights and different modes. J. Contemp. Dent. Pract., 8: 52-59. PMID: 17277827

Zafar, M.S. and N. Ahmed, 2015. Therapeutic roles of fluoride released from restorative dental materials. Fluoride, 48: 184-194.

Zafar, M.S., 2013. Effects of surface pre-reacted glass particles on fluoride release of dental restorative materials. World Applied Sci. J., 28: 457-462. DOI: 10.5829/idosi.wasj.2013.28.04.1869 